\title{
O ETANOL DE SEGUNDA GERAÇÃO E SUA IMPORTÂNCIA ESTRATÉGICA ANTE O CENÁRIO ENERGETICO INTERNACIONAL CONTEMPORÂNEO
}

\author{
Geraldo Jose Ferraresi de Araujo ${ }^{1}$ \\ Luiz Felipe Scaranti Navarro² \\ Bruno Antonio Santana Santos ${ }^{3}$
}

RESUMO: O etanol de segunda geração se apresenta como uma tecnologia capaz de fazer frente aos desafios energéticos internacionais contemporâneos: alta do preço do petróleo nos mercados internacionais, dependência dessa fonte por determinados países, aquecimento global e a demanda crescente de etanol de primeira geração tanto no mercado nacional quanto internacional. Ante o exposto, o objetivo desse artigo é dissertar sobre a expansão do mercado de etanol e no mundo, a importância do etanol de segunda geração ante a essa realidade e os desafios a serem superados pelo Brasil para não perder a segunda onda da inovação neste produto e a sua opção ante a estratégia energética nacional. Para tanto, a metodologia utilizada foi a do tipo qualitativa através do levantamento bibliográfico. A bibliografia foi levantada pela internet no período de 01/04/2010 até 25/07/2013, com enfoque em fontes de energia, expansão do mercado de etanol de primeira e segunda geração. Portanto o Brasil, um dos maiores produtores de etanol do mundo, para continuar como um player importante nesse mercado precisa melhorar as relações entre universidades, institutos de pesquisa, empresas de energia e

\footnotetext{
${ }^{1}$ Bacharel em Administração pela Faculdade de Economia, Administração e Contabilidade de Ribeirão Preto da Universidade de São Paulo (Avenida dos Bandeirantes 3900, CEP14040-900 - Ribeirão Preto/SP, Brasil). E mail: geraldoferraresi@gmail.com. Fone: 55163602 - 3916. Fax: 5516 3633-4411.

${ }^{2}$ Bacharel em Administração de Empresas na Faculdade de Agricultura e Ciências Veterinárias da Universidade Estadual Paulista Julio de Mesquita Filho de Jaboticabal (Via de Acesso Prof. Paulo Donato Castellane SN, CEP14884-900, Jaboticabal /SP, Brasil).E mail: luizsnavarro@gmail.com. Telefone: 5516 3209-2624. Fax: 5516 3209-2625.

${ }^{3}$ Bacharel em Engenharia de Produção pela Universidade de Franca (Avenida Doutor Armando Salles Oliveira, 201, CEP 14404-600 - Franca -SP/Brasil). E mail: bruno.alirp@gmail.com. Fone: 55 16 8854-5182.
} 
agências de fomento para consolidação da produção em larga escala do etanol celulósico e com isso afirmar sua posição estratégica na produção desse combustível. Outrossim, ante o cenário nacional não se pode deixar de utilizar a biomassa para a produção de energia elétrica, onde o país ainda deficitário e o mesmo tem importância para 0 crescimento econômico, bem estar de defesa do Brasil.

Palavras Chave: Energia. Consumo de Biocombustiveis. Etanol de Segunda Geração.

\section{INTRODUÇÃO}

A energia tem importância superlativa no planejamento estratégico, tático e operacional das nações, questões ligadas a política de desenvolvimento econômico, operacionalização da sociedade e segurança nacional são decididas também com base na capacidade energética de cada país.

Porém, grande parte da energia consumida no mundo é oriunda de fontes não renováveis, como o petróleo e o carvão mineral. Essa situação coloca grande parte dos países do mundo em situação de vulnerabilidade estratégica, devido: a possibilidade de esgotamento desses recursos mesmo em longo prazo, oscilação dos preços nos mercados internacionais e conseqüentemente de todos os seus derivados; um dos grandes responsáveis pelo aquecimento global e seus desdobramentos, de acordo com Conejero (2006): derretimento das calotas polares, aumento do nível dos oceanos, aumento da incidência de doenças transmissíveis por mosquitos e outros vetores (malária, febre amarela e dengue), alteração no regime pluvial, intensificação de fenômenos climáticos extremos (secas, inundações, ciclones e tempestades tropicais), desertificação, perda de áreas agricultáveis, problemas relacionados ao abastecimento de água doce e aumento de fluxos migratórios; chuvas ácidas; ilhas de calor e problemas respiratórios na população dos grandes centros urbanos.

Ante os problemas apontados acima, claramente contrários dimensão social e ambiental da sustentabilidade, a busca por fontes renováveis de energia que contemple o tripé da sustentabilidade se acelerou no final do século XX.

Nesse sentido, embora o Brasil seja uma exceção a regra com $46,8 \%$ de sua matriz energética composta por fontes renováveis de energia como usinas hidroelétricas, 
biomassa e o etanol de cana de açúcar, o mundo tem buscado energia renováveis como: eólica, solar, geotérmica, biodiesel e maré motriz, porém, todas essas ainda não são produzidas em grandeza de escala e não possuem preços competitivos para substituírem o petróleo, carvão mineral e a energia nuclear como fonte principal de energia.

Todavia, o etanol, fonte renovável de energia, oriunda da cana de açúcar, milho e beterraba já é produzida em larga escala, sobretudo no Brasil e nos Estados Unidos para suprir a demanda de veículos movidos a etanol. Contudo a produção de etanol de primeira geração oriunda do milho e da beterraba compete diretamente com produção de alimentos derivados desses, o que converge em um processo inflacionário dos alimentos em escala mundial (devido a oferta insuficiente dos produtos derivados do milho e da beterraba e na outra ponta uma demanda crescente) o que contribui para o crescimento da insegurança alimentar em escala mundial.

Sendo crescente a demanda por energia renovável, limpa e em grandeza de escala sem comprometer a segurança no fornecimento de alimentos, está em curso uma corrida internacional entre empresas de energia, laboratórios de pesquisa e universidade para obtenção do etanol de segunda geração.

O etanol de segunda geração, para Romero (2008) produzido a partir da celulose, presente nos resíduos da cana-de-açúcar e em outras matérias-primas vegetais, é uma alternativa fundamental aos cerca de cem países capazes de produzir o combustível renovável e que desejam fazê-lo sem prejudicar a produção de alimentos. Além disso, projeções indicam que esses processos poderiam aumentar o rendimento de produção de etanol por hectare em até 100\%. (Szwarc, 2008).

Ante o exposto, o objetivo desse artigo é dissertar sobre a expansão do mercado de etanol e no mundo, a importância do etanol de segunda geração ante a essa realidade e os desafios a serem superados pelo Brasil para não perder a segunda onda da inovação neste produto e a sua opção ante a estratégia energética nacional.

Para tanto a metodologia utilizada neste artigo foi a do tipo qualitativa através do levantamento bibliográfico. Em linhas gerais essa é uma pesquisa de toda bibliografia já publicada em artigos, revistas, dissertações, teses, livros, monografias, ensaios e publicações avulsas que já dissertaram o tema investigado pelo pesquisador em sua atividade cientifica. 


\title{
Then Fórum Ambiental
}

da Alta Paulista

ISSN 1980-0827

Volume 9, Número 5, 2013

Direito Ambiental,

A bibliografia foi levantada pela internet no período de 01/04/2010 até 25/07/2013, com enfoque em fontes de energia, expansão do mercado de etanol de primeira e segunda geração.

\section{A QUESTÃO ENERGETICA BRASILEIRA E INTERNACIONAL}

A questão energética esta ligada diretamente com o desenvolvimento das nações e do mundo. No mundo inteiro, para Sene e Moreira (2010, p. 239)

\begin{abstract}
o setor energético é considerado estratégico e quase sempre é controlado pelo estado através de políticas de planejamento da produção, concessão de exploração a grupos privados ou intervenção direta na produção através de empresas estatais. A estrutura energética insere-se diretamente na economia a na geopolítica: produção industrial, sistema de transporte, segurança, saúde, educação, lazer, comércio, agricultura. Qualquer colapso na produção ou elevação de seus custos afeta o cotidiano de todas as atividades desenvolvidas no país, na posição da nação no comercio internacional, na composição dos custos de produção e na competitividade da empresa e do país.
\end{abstract}

Os constantes crescimentos econômicos mundial, sobretudo dos países emergentes, têm conduzido a uma dependência cada vez mais acentuada de fontes de energia não renováveis como carvão, petróleo, gás natural. Para o Portal do Ambiente e do Cidadão (2013) como o nome indica "não renovável" significa que o seu período de regeneração e utilização implica, num maior ou menor prazo, em seu esgotamento.

Com a crescente preocupação sobre a disparada do preço do petróleo nos mercados internacionais, estar disponível em poucos países e da discussão mundial sobre os modos operantes da diminuição das emissões dos gases efeito estufa tem ocupado o centro das atenções nacionais e internacionais para a busca e investimento em outras fontes de energia.

O Brasil passou, no inicio dos anos 2000 por uma escassez de energia elétrica, que impactou negativamente no seu crescimento econômico naquele período. Porém, o país ainda enfrenta alguns problemas energéticos, embora a situação esteja melhor no inicio da segunda década do século XXI. Por isso, há uma grande preocupação do governo com a produção de energia.

No Brasil, 46,8\% da energia consumida em 2007, provieram de fontes renováveis, valor acima da média mundial de apenas 14\%. Para Brancati (2009) o Brasil tem buscado projetos energéticos, como a exploração da camada pré-sal, um investimento estratégico, 
pois aumentará a importância do Brasil na economia mundial, além de tornar o país autosuficiente na produção de gás natural.

Também tem buscado projetos energéticos que causem menores impactos ambientais. Isso pode ser verificado com o expressivo aumento do número de usinas com de biomassa e com pesquisas de novas fontes renováveis, como os bio combustíveis, produtos à base de plantas e das quais se produz o biodiesel e o etanol da cana-deaçúcar.

\section{O ETANOL}

Para CEMIG (2012) o etanol ou álcool etílico é um líquido incolor, volátil e inflamável. Sua fórmula molecular é $\mathrm{C} 2 \mathrm{H} 5 \mathrm{OH}$ e é quimicamente classificado como um álcool, isto é, possui um grupo hidroxila $(\mathrm{OH})$ ligado a um $\mathrm{CH} 2$.

Para Pacheco (2011) o etanol é uma alternativa para diminuir problemas ambientais e energéticos no mundo em razão da escassez e alta dos preços dos combustíveis fósseis e da poluição por eles causada. O Brasil encontra-se em uma posição destacada no que se refere à produção de etanol, por apresentar vantagens na tecnologia de produção, liderança na agricultura de energia e mercado de biocombustíveis sem ampliar a área desmatada ou reduzir a área destinada à produção de alimentos. Além disso, a matriz energética brasileira já é um exemplo de sustentabilidade, pois enquanto a média mundial é o uso de apenas $14 \%$ de fontes renováveis, o Brasil utiliza $46,8 \%$ dessas fontes.

Segundo a União da Indústria de Cana-de-açúcar (2012), foram produzidos, no país, 20,5 bilhões de litros do combustível na safra 2011-2012.

Para Kohlhepp (2010) atualmente há 359 destilarias de etanol no estado de São Paulo. Hoje, a distribuição de destilarias é como segue: 43\% em São Paulo; $9 \%$ em Minas Gerais; 8\%, havendo tendências de descentralização para o Mato Grosso do Sul, para o Triângulo Mineiro e para Goiás (Geomapas, 2008). Com investimentos de US\$10 bilhões e créditos baratos do BNDES, mais 113 destilarias estavam planejadas até 0 ano de 2010/2011.

A procura mundial de biocombustíveis aumentou devido ao preço recorde do petróleo, vendido acima de US\$140/barril em junho de 2008. Assim, o interesse no Brasil, 
além dos fatores de ambientais, foca: na substituição da gasolina no mercado interno e também na possibilidade de fornecimentos de etanol em grande escala para o mercado internacional. (KOHLHEPP, 2010). Para Petrobras (2011) uma perspectiva para o etanol brasileiro se abriu no final de 2011, quando o Congresso dos Estados Unidos da America, revogou a taxação imposta ao biocombustível do Brasil e suspendeu o subsídio aos produtores locais.

O Japão também é um mercado em potencial, na medida em que não possui áreas suficientes para o plantio de matéria-prima para a produção de biocombustíveis, intenciona misturar pelo menos $10 \%$ de etanol à gasolina e ficará dependente de importação em larga escala. Na União Européia, a mistura (hoje de $2 \%$ ) deverá ser de $5,75 \%$ de etanol (extraído da beterraba) a partir de 2012 e de $10 \%$ a partir de 2020 . Segundo o Banco Nacional de Desenvolvimento Econômico e Social, dependendo dos números da exportação do etanol, espera-se para 2017 um colheita de 1 bilhão de toneladas. Os conflitos de interesse com a produção de gêneros alimentícios podem ser evitados pelo aumento de produtividade e não pela duplicação da área cultivada. (KOHLHEPP, 2010).

E na trajetória para se tornar uma commodity global, o desenvolvimento do chamado etanol celulósico ou de segunda geração é fundamental.

\section{ETANOL DE SEGUNDA GERAÇÃO}

A busca do etanol extraído de celulose está mobilizando um número crescente de pesquisadores ao redor do mundo, estimulados por políticas de pesquisa voltadas para ampliar a produtividade no setor bioenergético (Marques, 2009). Projeções indicam que esses processos poderiam produzir cerca de 300 litros de etanol por tonelada de bagaço seco, aumentando o rendimento de produção de etanol por hectare em até $100 \%$. (Szwarc, 2008).

Além disso, o etanol celulósico apresenta grande potencial de crescimento, pois não depende da produção de alimentos para sua industrialização e nem da expansão da área plantada com cana-de-açúcar, e sim do reaproveitamento dos resíduos da produção 
de etanol e açúcar, como o bagaço e na palha da cana, que são fontes de celulose e respondem por dois terços do potencial energético da planta. A principal vantagem do bagaço está na logística, pois, como se trata de um co-produto da cana que já está disponível na usina, não há necessidade de implantação de infra-estrutura de coleta e de transporte.

Ante o exposto "Há uma corrida mundial pelo desenvolvimento do etanol celulósico", diz Rubens Maciel Filho, professor da Faculdade de Engenharia Química da Unicamp. (Marques, 2009).

Nos EUA, o governo federal e empresas de capital de risco têm financiado as pesquisas científicas com centenas de milhões de dólares. Outros centros avançados de pesquisa, como o Canadá, o Japão e os países nórdicos também vêm conduzindo programas de pesquisa nessa área, como afirma o artigo eletrônico "Pesquisas de multinacionais ameaçam liderança do etanol brasileiro" de Castro (2009) para o Estado de Minas, onde afirma:

Os investimentos de milhões de dólares mostram que a aposta em um novo combustível líquido é mesmo para valer. Entre os gigantes estão empresas sediadas nos Estados Unidos, como Texas Pacific Group, incorporada à KKR por US\$ 45 bilhões, e a Amyris Biotechnologies, que investe cerca de US\$20 milhões em pesquisas sobre o produto de segunda geração. Outros gigantes como as americanas Diversa e Celunol e Dupont e a British Petrol, do Reino Unido, avançam na corrida pelo combustível de segunda geração, assim como a canadense Husky Energy. A americana Chevron firmou parceria com o Departamento de Energia dos Estados Unidos com investimentos de nada menos que US\$1,5 bilhão em projetos de energia renovável.

No Brasil, apesar dos investimentos serem mais modestos, há importantes iniciativas em curso. O Ministério de Ciência e Tecnologia coordena um projeto que envolve um grupo de universidades. Além disso, o Centro de Tecnologia Canavieira, a Petrobrás, a Dedini e a Oxiteno também desenvolvem trabalhos nesse campo. (Szwarc, 2008).

Para acelerar o desenvolvimento em escala comercial do etanol de segunda geração no Brasil o BNDES vai investiu $R$ \$ 600 milhões na usina pioneira da GraalBio, que terá capacidade para produzir 82 milhões de litros/ano. (Info Energia, 2013).

O Plano Estratégico 2011-2015 da Petrobras prevê investimentos de US $\$ 1,9$ bilhão para ampliar a produção de etanol, com a construção de novas usinas e destilarias, o aumento da capacidade de moagem e a renovação de canaviais. Mais US\$1,3 bilhão 
serão investidos em logística e outros US\$300 milhões em pesquisa e desenvolvimento de novas tecnologias.

Para o Brasil, o domínio da tecnologia tem potencial de consolidar de vez o status do país como o maior produtor de biocombustíveis. A situação do país é privilegiada por dois motivos. O primeiro é que a infra-estrutura para produzir etanol já está montada e o conhecimento sobre o combustível acumulado pelos cientistas. A segunda vantagem é o custo da matéria prima, o bagaço da cana está disponível nos pátios das usinas e não representará custo. (Nassif, 2010).

Todavia, para Marques

[...] Brasil tem cinco anos para vencer os desafios tecnológicos. "Caso contrário, estaríamos dependentes de processos e insumos importados. Mas o esforço vale a pena porque levamos a vantagem de ter a matéria-prima, que é o bagaço, disponível na unidade de produção de etanol". (Marques, 2009)

Dado toda a movimentação cientifica em busca da produção em larga escala do etanol de segunda geração, a desvantagem brasileira na corrida pela segunda onda de inovação na produção desse produto é a importância desta pauta para os interesses nacionais, faz-se necessário uma maior articulação de esforços entre universidades, institutos de pesquisa, empresas e agências de fomento, com o objetivo de alcançar o projeto dominante e conseqüentemente consolidar as inerentes vantagens competitivas do Brasil na produção deste combustível.

O Brasil como líder mundial na produção de biocombustiveis, tem sua liderança ameaçada pela consolidação do projeto dominante da segunda onda de inovação da produção de etanol, conseqüentemente colocando sua liderança em risco e provocando uma crise em toda cadeia produtiva sucroalcooleira, com impactos sociais e econômicos para todo o país.

Se consolidado pelo país, a combinação da produção de etanol de primeira e segunda geração permitirá obter maior quantidade de combustível sem aumentar o volume de matéria-prima cultivada nem a área plantada, mas, em conseqüência, ter-se-á menor disponibilidade de bagaço para geração de energia elétrica. No momento em que a tecnologia de segunda geração estiver em escala comercial, as usinas seguirão a lógica do mercado, voltando sua produção para eletricidade ou etanol, de modo semelhante ao 
que ocorre com a destinação do caldo, que a depender das condições produz mais etanol ou mais açúcar. (Pacheco, 2011).

Vários especialistas defendem a idéia de que, no momento, o Brasil precisa mais de energia elétrica do que de combustíveis líquidos, e que a utilização de bagaço para produção de etanol não seria benéfica, visto que o país sofreu, há pouco tempo, uma restrição no desenvolvimento econômico e social devido ao racionamento de energia elétrica. Entretanto, é imprescindível que o país mantenha sua liderança mundial no campo dos biocombustíveis e garanta produção suficiente para atendimento da demanda nacional e parte de demanda externa. (Pacheco, 2011).

\section{CONCLUSÃO}

Com o aumento do preço do petróleo nos principais mercados internacionais, conseqüentemente seus derivados, o agravamento da concentração de gases efeito estufa na atmosfera e as conseqüências do aquecimento global e sendo a questão energética estratégica para o desenvolvimento, bem estar e segurança das nações, essas procuram por fontes alternativas de energia capazes de serem produzidas em larga escala, renováveis e limpas, dentre todas as opções o etanol se apresenta como uma opção viável. Porém, mesmo sendo essa uma alternativa possível ante os desafios apresentados acima, a crescente demanda tanto mercado nacional quanto internacional faz-se necessário um salto qualitativo e quantitativo em sua produção, ou seja, um aumento da quantidade de etanol produzido pela mesma quantidade de biomassa, sem competir com a produção de alimentos.

O etanol de segunda geração através do bagaço da cana de açúcar é uma das melhores opções ao presente momento histórico ante do aquecimento global, preço recorde do petróleo e seus derivados e o aumento da demanda no mercado nacional e internacional por biocombustiveis.

Porém o Brasil, um dos maiores produtores de etanol do mundo tem todas as prerrogativas para continuar como um player estratégico no mercado energético internacional, porém precisa melhor articular a relação entre universidades, institutos de pesquisa, empresas de energia e agências de fomento para consolidação do projeto 
dominante o projeto dominante e conseqüentemente consolidar as inerentes vantagens competitivas do Brasil na produção deste combustível.

\section{REFERÊNCIAS}

BRANCATI, Lucas. A questão energética. Disponível em:<http://lucasbrancati.blogspot.com.br/2009/03/questao-energetica.html>. Acesso em 24 jul.2013.

CEMIG. Alternativas Energéticas: Uma visão CEMIG. Disponível em:<http://www.cemig.com.br/ptbr/A_Cemig_e_o_Futuro/inovacao/Alternativas_Energeticas/Documents/Alternativas\%20E nerg\%C3\%A9ticas\%20-\%20Uma\%20Visao\%20Cemig.pdf/>. Acesso em 24 jul.2013.

CONEJERO, Marco. Antonio. Marketing de créditos de carbono: um estudo exploratório. 2006. Dissertação (Mestrado em Administração) - Faculdade de Economia, Administração e Contabilidade de Ribeirão Preto, Universidade de São Paulo, Ribeirão Preto, 2006.

ESTADO DE MINAS. Pesquisas de multinacionais ameaçam liderança do etanol brasileiro. Disponível

em:<http://wwo.uai.com.br/UAl/html/sessao_4/2009/11/16/em_noticia_interna,id_sessao= 4\&id_noticia=136145/em_noticia_interna.shtml>.Acesso em: 1 jun. 2010.

GEOMAPAS. Usinas de etanol e açúcar das regiões Centro-Sul e Norte/Nordeste 2007. São Paulo, 2008.

INFO ENERGIA. Pílulas Energéticas. Disponível em: <http://www.infoenergia.com.br/paginas/noticias.asp?codigo=6833->. Acesso em 24 jul.2013.

KOHLHEPP, Gerd. Análise da situação da produção de etanol e biodiesel no Brasil. Estudos Avançados., São Paulo, v. 24, n. 68, 2010 Disponível em:

$<$ http://www.scielo.br/scielo.php?script=sci_arttext\&pid=S0103$40142010000100017 \&$ Ing=en\&nrm=iso >. Acesso em 24 jul.2013.

MARQUES, Fabrício. O alvo é o Bagaço. Revista Pesquisa FAPESP. Disponível em: <http://revistapesquisa.fapesp.br/extras/imprimir.php?id=3934\&bid=1>. Acesso em: 14 de Abr. 2010.

NASSIF, Luiz. Empresas dinamarquesas anunciam tecnologia para fazer etanol de bagaço de cana. Portal IG. Disponível 


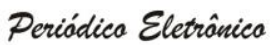 \\ Fórum Ambiental}

da Alta Paulista
ISSN 1980-0827

Volume 9, Número 5, 2013

Direito Ambiental, Políticas Públicas e Sociedade

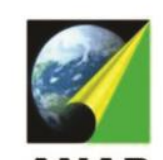

ANAP

em:<http://colunistas.ig.com.br/luisnassif/2010/02/26/o-etanol-de-segunda-geracao/>. Acesso em: 14 de Abr. 2010.

PACHECO, Thályta Fraga. Produção de Etanol: primeira ou segunda geração?Disponível em:

<http://www.embrapa.br/embrapa/imprensa/artigos/2011/producao-de-etanol-primeira-ousegunda-geracao\#>. Acesso em 24 jul.2013.

PETROLEO BRASILEIRO. Etanol: Um salto para o futuro. Disponível em:

<http://www.petrobras.com/pt/magazine/post/detalhe-18.htm>. Acesso em 24 jul.2013.

PORTAL DO MEIO AMBIENTE E DO CIDADÃO. Sobre questões energéticas.

Disponível em:<http://ambiente.maiadigital.pt/ambiente/energia/mais-informacao-1/sobreas-questoes-energeticas/>. Acesso em 24 jul.2013.

ROMERO, Thiago. Etanol de segunda geração é essencial à sustentabilidade dos bicombustíveis. Disponível

em:<http://www.inovacaotecnologica.com.br/noticias/noticia.php?artigo=etanol-desegunda-geracao-e-essencial-a-sustentabilidade-dos

biocombustiveis\&id=010115081226>. Acesso em 24 jul.2013.

SENE, Eustáquio; MOREIRA, João Carlos. Geografia Geral e do Brasil: Espaço Geográfico e Globalização. 4.Ed. São Paulo. Editora Scipione. 2010.

SZWARC, Alfred. Na rota do etanol de segunda geração. Agro Rede Noticias. Disponível em: <http://www.agroredenoticias.com.br/textos.aspx?QN3amXBlbo8HXMSeW3S06g> Acesso em: 14 de Abr. 2010.

União da Indústria de Cana de Açúcar. Usina pioneira de etanol celulósico coloca Brasil entre os lideres globais no uso da nova tecnologia. Disponível em:

<http://www.unica.com.br/noticia/29810917920343378786/usina-pioneira-de-etanolcelulosico-coloca->. Acesso em 24 jul.2013.

SENE, Eustáquio; MOREIRA, João Carlos. Geografia Geral e do Brasil: Espaço Geográfico e Globalização. 4.Ed. São Paulo. Editora Scipione. 2010 